\title{
Papyri Supply Materials Recipes from the 3rd Century AD
}

In 1828, the Netherlands government bought a cache of ancient Greek papyri that a Swedish official in Alexandria had acquired in Thebes. They were deposited in the Museum of Antiquities in Leyden, but not until 1885 were translations of the entire collection made public. Among them was Leyden Papyrus X, which proved to be a rare window on ancient thought about materials as well as the antiquity of industrial fraud. The first full English translation appeared in 1926, along with a commentary, in the Joumal of Chemical Education.

Written toward the end of the 3rd century A.D., the Leyden Papyrus is a list of recipes intended for artisans who catered to the hunger of the ancient Egyptian middle class for precious objects, or at least what appeared to be precious objects. Collectively, the recipes are testimony to the power of empirical discovery harnessed by ancient artisans. Most of the recipes are metallurgical, many of them almost alchemical in spirit as they describe ways for imitating the appearance of precious metals. Fifteen recipes are for writing in gold and silver. Eleven focus on making and using dyes, especially purple, which was associated with the elite class.

The papyrus reveals little about the theoretical views that the author may have had about the recipes' materials, ingredients, and transformations. Chemical identifications for substances that had proven useful for specific purposes often hinge on the exact places where the materials were originally found rather than on a more general scientific principle or feature of the substances. Recipe 2, for example, as a way to refine tin, calls for "salt of Cappadocia" and "stone of Magnesia," probably referring to what chemists now call common salt and iron oxide, respectively. Recipe 95 calls for "stone of Phrygia" for preparing a purple dye.

As for metals, the most important distinguishing factor for the author was appearance, not actual compositional differences. If the product looked like gold, silver, or electrum (an alloy of gold and silver) it was called "asem" regardless of which alloying ingredients went into the recipe. A few recipes clearly reveal the deceptive intentions that underlie much of the Papyrus. Recipe 8, for example, converts tin and a copper alloy into an "asem of the first quality, which will deceive even the artisans."

The various recipes for purple dyes suggest that the Papyrus was intended for workshops catering to the nobility. Ironically, the recipes reveal that the dye could be made in many inexpensive ways besides extracting it from particular shellfish, which is how most historians have portrayed the color's provenance.

Now and again, a recipe used cryptic language for ingredients, perhaps as a means of restricting success to those who were somehow "in the know." To write in letters of gold without using gold, several recipes call for the bile of river tortoises or goats. Mother's milk and the urine of a young boy are also called for intermittently. In subsequent centuries, alchemists developed these instructions into a type of encryption to such a degree that by Newton's day alchemical treatises were virtually impenetrable except by initiates.

For decades after the Leyden Papyrus had come to the attention of scholars, there was little reason to think there might have been other relevant documents among the original acquisition from Thebes. It turns out, however, that some of the papyri from Thebes ended up at the Swedish Academy of Antiquities at Stockholm and remained there unnoticed until 1906 when they were transferred to the Victoria Museum in Upsala. There, a papyrus that became known as the Stockholm Papyrus was translated and found to be at least partly written by the same aúthor as the Leyden Papyrus X.

The Stockholm Papyrus is thin on metallurgy and fat on dyeing, imitating precious stones, and other procedures that are consistent with the idea that the recipes cater to ancient middle class hunger to appear richer than they actually were. Recipe 18, for example, explains how to prepare fake pearls from mica that had been grounded into a powder. The procedure involves mixing the mica into a wet, malleable paste with gum, wax, mercury, and egg white. Upon drying, the material can be cut, shaped, and brought to a high polish. The author claims with some pride that "if managed properly [the product] will exceed the natural."

Many other recipes in the Stockholm Papyrus are devoted to imitations of emerald, ruby, amethyst, beryl, and other precious and expensive gem stones. Several recipes for preparing stones to receive various colors call for "garlic." Recipe 51 reveals "garlic" as a cryptic term referring to human excrement. The recipes devoted to dyes and dyeing reveal that the craft had already, in the 3rd century A.D., reached a level of development that would not change fundamentally until the advent of coal tar dyes 1,500 years later. The same agents for cleaning and preparing cloth to hold dyes were already in use.

Among the more offbeat items is Recipe 25, which must have been discovered by an ancestor of today's biotechnologists. To make a dark pearl white, "give it to a cock to swallow, cut him open immediately, and you will find that the pearl has become white." Nothing like a wash with acidic stomach juices! Recipe 60 is a hardly pleasing alternative. It instructs the reader to fish the ingested and cleaned pearl from the rooster's excrement. Choose your evil.

The final two-sentence item that links the two papyri might shed some light on the author or authors. It reads like a prayer suggesting that the author was a member of the priestly class. The first sentence asks that a listed roster of Egyptian gods accept the author "who comes before" them. The second sentence reads in translation as follows: "Trust thyself (to the Gods), anoint thyself and thou shalt see him with thine eyes." The material and spiritual worlds apparently cohabited naturally within this putative author even as he instructed others in various arts of deception.

IvAN AMATO

FOR FURTHER READING: E.R. Caley, Journal of Chemical Education 3 (1926), pp. 1146-1149; Journal of Chemical Education 4 (1927) pp. 979-1002; R.P. Multhauf, "The Science of Matter," Science in the Middle Ages, edited by D.C. Lindberg (University of Chicago Press, Chicago, 1978) pp. 373-374; H. Salzberg, From Caveman to Chemist (American Chemical Society, Washington, DC, 1991) p. 36; E.J. Holmyard, Alchemy (Dover Publications, New York, 1990) p. 27. 


\section{Subscribe to the Journal of Materials Engineering and Performance Now...}

The Journal of Materials Engineering and Performance presents information that's invaluable for solving day-to-day engineering challenges in real-world applications. This bi-monthly journal covers all aspects of materials selection, design, characterization, processing, testing and performance used in engineering applications, and does it through $900+$ pages per year packed with case studies, examples, illustrations, technical notes, reports from national labs, guest comments and editorials, literature abstracts and more.

Send for your FREE Preview Package now and receive this special subscription price (first-time subscribers only). and Save 20\%.

Please send me my FREE Preview Package I I Name Title Journal of Materials Engineering and Performance
I Company Name

I Address

I City

I Phone

Fax E-mail cals

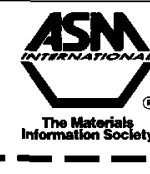
Materials Park, Ohio 44073-0002

\section{LIBRARY}

\section{An Introduction to Metal Matrix Composites}

T.W. Clyne and P.J. Withers

(Cambridge University Press, 1993) ISBN: 0-521-48357-3

The book, An Introduction to Metal Matrix Composites, by T.W. Clyne and P.J. Withers, with a length of approximately 500 pages, discusses essentially all important aspects of continuously and particulate reinforced metal matrix composites. It consists of a description of basic composite mechanics followed by Eshelby's inclusion approach to the modeling of composites. This theoretical framework predicts properties such as composite elastic constants, residual stresses arising from cooling, and the stress required for the onset of inelastic deformation. The derived equations are illustrated with numerous experimental examples. A description of the plastic deformation of composites identifies the reasons for their tension-compression asymmetry and for their often low proportional limits. Similarly, the book discusses and illustrates creep properties, including the dramatic enhancement of creep by thermal cycling. The mechanical properties of the interfacial region between the matrix and the reinforcing phase are, of course, very important. In particular, the book describes and illustrates the measurement of the mechanical properties of interfaces, for example, by fiber push-out tests. Based on such measurements, expressions for the energy absorption of composites during fracture are derived. The authors' discussion of the influence of reaction layer thicknesses on composite strength is followed by a description of the interfacial chemistry leading to such reaction layers.

A chapter on fracture and failure deals with issues such as crack/void nucleation and growth, failure strain, and fracture toughness as a function of reinforcement volume fraction. The book addresses also thermal and electrical conduction as well as miscellaneous properties such as tribological behavior, mechanical damping, and environmental effects. Other chapters are devoted to fabrication techniques for composites, the development of the matrix microstructures in composites (which is influenced by the reinforcing phase), and testing and characterization techniques. The book concludes with a chapter on applications of metal matrix composites, which contains a number of case studies of successful composites.

The authors present, as far as possible, composite behavior in terms of simple, easily derived equations. At the same time, they are careful to point out the limitations of the individual approaches. The authors provide ample literature references in case the reader intends to follow up on a particular topic. Whenever possi- 